\title{
How to improve the satisfaction levels of new rural cooperative medical system in underdeveloped areas of China?
}

Pin YaoShengjing Hospital of China Medical University

Shengjing Hospital of China Medical University

Yifan WuSchool of Nursing, China Medical University

School of Nursing, China Medical University

Xiaodong Chen

School of public health, Xinjiang Medical University

Jing OuYang

Humanity and Management College, Shaanxi University of Chinese Medicine

Chunping Liu

Associate Professor of Administration School, Hainan Medical University

Shu Sun ( $1460089984 @ q q . c o m$ )

Department of Burns, The First Affiliated Hospital of China Medical University. https://orcid.org/00000002-8053-5640

Research article

Keywords: NRCMS, Beneficiary, Medical resource, Surveys, Health policy

Posted Date: September 19th, 2019

DOI: https://doi.org/10.21203/rs.2.14667/v1

License: (c) (i) This work is licensed under a Creative Commons Attribution 4.0 International License.

Read Full License 


\section{Abstract}

\section{Abstract}

Background: Over the years, China has designed a new rural cooperative medical system for large rural population, which enables them to obtain adequate medical services and prevents poverty caused by medical treatments. However, the rapid economic growth makes the allocation of health resources and the efficient utilization of health services face severe challenges. The study aims to reveal the medical inequality of eight underdeveloped provinces from the perspectives of medical institutions, insurance policies, the government and farmers, in order to puts forward relevant recommendations.

Methods: The relevant statistics about assessing the characteristics and equity of demographics, socioeconomic and geographical dimensions were from the China Statistical Yearbook and the China Health Statistics Yearbook. A face-to-face sampling survey of farmers in 24 counties of eight less developed provinces (Guizhou, Yunnan, Sichuan, Shanxi, Gansu, Qinghai, Ningxia and Xinjiang) was carried out by multi-stage stratified random sampling. The protection effect of New Rural Cooperative Medical System

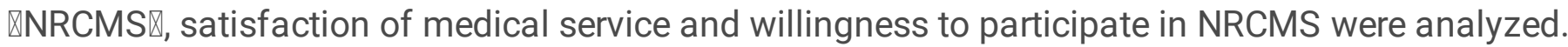

Results: Since the implementation of the new rural cooperative medical system, there has been an inequality in medical service and insurance policy among poor residents in western China. The uneven distribution of medical resources, the inadequacy of local government investment, the complexity of the reimbursement process, and the low amount of compensation resulted in only $26.6 \%$ of the population believing that the economic burden of the disease had been reduced, and $57.3 \%$ that the relief effect was not obvious. The remaining $16.1 \%$ thought the system was ineffective and farmers' satisfaction was not enough.

Conclusion: Compared with the eastern and central regions, there was a certain degree of unfairness in government investment in the resources of medical institutions of the western region with new rural cooperative medical care. This study suggested that policy makers can attract high-quality medical staff to the western region by providing economic security and improving policies. In addition, the increase of the government regional health expenditure and supervision propaganda was one of the important ways to improve the farmers' satisfaction with the policy.

\section{Background}

According to the data from World Bank, rural population made up $51.0 \%, 61.7 \%$ and $72.4 \%$ of the total population in middle income, lower-middle income and low income countries respectively in 2010 [1]. In 2017, the agricultural population of China reached 576.61 million, and the rural population accounted for a considerable proportion of the total population $[2,3]$. The extent of medical development is related to the basis for social stability and progress, it is also an important indicator of the country's economic prosperity, especially for developing countries that have a large rural population and drastic rural-urban income disparity. With the economic miracle in the recent thirty years, most well developed places in 
China keep a fast and steady pace in the development of medical care system, but the pace of less developed areas is rather slow[4]. One of the important reasons is the imbalance of the economic level, which leads to the serious imbalance in the rural medical insurance system and the health care system.

Compared with urban residents, rural residents belong to low-income groups. They do not have the privilege of health insurance, which undoubtedly exacerbates the urban-rural income gap and poses a potential threat to long-term social stability. In order to solve this problem, the Chinese government put forward the New Rural Cooperative Medical System(NRCMS)[5], which aims to improve rural medical and health conditions, lighten the burden of farmers' medical expenses, solve the problem of difficulty in seeing a doctor, improve the health level of farmers, promote the development of rural economy and maintain social stability[6]. Since the establishment of this system focuses on solving the problem of poverty caused by disease and those who return to poverty due to serious diseases such as infectious diseases and endemic diseases, it can effectively help farmers to enhance their ability to resist major disease risks.

The NRCMS had the following characteristics: (1) adoption of principles and methods of modern insurance system; new fundraising, modern compensation and payment mechanisms; (2) voluntary participation; (3) broader coverage; and (4) different implementation with local conditions[7].

However, through the analysis of former studies, we find the study targets come up with some shortage. Babiarz KS found that NRCMS provides some financial risk protection for individuals in rural China and has partly corrected distortions in Chinese rural healthcare [8]. That is, most of those researches were discussing based on the system itself but not on the relationship between the system and the beneficiary, especially the participating farmers during the establishment and perfection of the system. It is more a general study of the system than the difficulties of less developed regions. In order to scientifically understand the factors that affect the fairness of the system, this study takes eight underdeveloped provinces of China as a sample, and reveals the medical inequality and the reason of the new rural cooperative policy in the underdeveloped provinces from four aspects: medical institutions, insurance policies, government and farmers. In addition, we also put forward strategic suggestions to help the New Rural Cooperative Medical System $₫$ NRCMS $₫$ achieve its policy goals in the future. The findings of the study can help understand the performance, the sustainability and future improvements of the NRCMS.

\section{Methods}

\section{Data Sources}

The data about health resources and health services of new rural cooperative medical care and government funds are collected from China Health Statistics Yearbook (2013 2016) and China Statistics Yearbook (2015 2016). All secondary data are publicly available. A sampling survey was conducted in 24 counties of 8 less developed provinces (Guizhou, Yunnan, Sichuan, Shanxi, Gansu, Qinghai, Ningxia and Xinjiang) by stratified multi-stage cluster sampling. Five townships and two villages or neighborhood 
committees were randomly selected in each county, and 15 to 18 people were randomly selected in each township. The interviewer firstly explained the purpose of the investigation, then followed by the investigation. This consent procedure is approved by the Ethics Committee of the Ministry of Health of China $₫[2013]$ 062】. This study revised the questionnaire recommended by the Ministry of Health and collected data on multiple public health issues through face-to-face interviews, including the following aspects: (1) the demand for and utilization of health services, mainly refers to the treatment of diseases, the reasons for meeting needs $\ a$ and the reasons for dissatisfaction; (2) the composition of medical insurance system, the scope of medical insurance, the scope and level of compensation, and the payment of medical expenses; (3) the satisfaction of farmers with the service system, service delivery process, coverage and level of medical insurance. All subjects were permanent residents of selected families. Under the supervision of doctors in township health centers or senior health institutions, a total of 2000 questionnaires were distributed. After removing the incomplete and ambiguous questionnaires, 1730 valid statistical data were finally obtained.

\section{Statistical analysis}

SPSS 20.0 and Mplus 7.0 were used for all analyses. Due to the enormous volume of data and the short time span, we performed a predominantly descriptive analysis that included frequencies, percentages, and other descriptive statistics. Using the latent variable growth model, the paper examines whether the government health expenditure in Guizhou, Yunnan, Sichuan, Shanxi, Gansu, Qinghai, Ningxia and Xinjiang shows linear growth in 2011-2016. After that, taking the per capita disposable income of every province from 2013 to 2016 as a covariable, this paper constructs a conditional model to examine whether the per capita disposable income causes the provincial differences in the initial level of government health expenditure and the speed of change. $p<0.05$ was taken as the requirement level of statistical significance.

\section{Results}

1.Regional economic level and income differences

- (1) Most participants of NRCMS live in the less developed regions and participants' income level influences their benefit from NRCMS[9,10], so the western region became the study target. In 2015, the per capita disposable income of the western region is 15,376.0 CNY, the lowest of the four regions in China (eastern: 25,954.0 CNY,central: 16,868.0 CNY, northeastern: 19,604.0 CNY) (National Bureau of Statistics of People's Republic of China, 2015).

- (2) From 2000 to 2015, the average net income of farmers from rural districts rises nearly 4 times, from 2253.4 CNY to 8895.9 CNY ( 1 USD $\approx 8.28 C N Y, 2000 ; 1$ USD $\approx 6.38$ CNY, 2015). However, the expense on medical care per capita rises 7 times, from $87.6 \mathrm{CNY}$ to $614.2 \mathrm{CNY}$. This makes the per capita medical care expenditure as a percentage of living consumption rises from $5.2 \%$ to $9.3 \%$ (Figure 1). 


\section{Figure 1 Per capita medical care expenditure as share of living expenditure of rural residents}

- 2.Medical and health service resources

- (1)By the end of 2015, 3.71 hospital beds and 3.90 medical technical personnels are shared by one thousand people in rural areas, while the national standard is 4.85 beds and 5.56 people. Except Xinjiang, at least one index is below the national average standard in the other seven provinces(Guizhou, Yunnan, Sichuan, Shanxi, Gansu, Qinghai and Ningxia) (Figure 2).

- (2) Compared with urban areas, medical technical personnels in poor rural medical institutions have a lower level of education, and the number of persons with various academic qualifications from more to less is college degree, high school, bachelor degree, junior high school and lower, and master degrees. Among them, the master's degree only accounts for $0.1 \%$. At the same time, $72.5 \%$ of the total number of medical technical personnels with junior professional title, $19.5 \%$ in intermediate titles and $2.2 \%$ in advanced titles. Compared with urban areas, both showed a serious imbalance in proportion (Table 1)

\section{Figure 2 Number of medical devices and beds per 1,000 persons in urban and rural areas of eight provinces}

\section{Table 1 The gap of doctor technology level between rural and urban districts}




\begin{tabular}{llll}
\hline Item & & Rural(\%) & Urban(\%) \\
\hline Education attainment & master degree & 0.1 & 15.1 \\
& bachelor degree & 11.8 & 50.9 \\
& college degree & 43.3 & 24.0 \\
\cline { 2 - 4 } & high school & 40.7 & 9.3 \\
\cline { 2 - 4 } Professional title & junior high school and lower & 4.1 & 0.8 \\
\cline { 2 - 4 } & advanced & 2.2 & 21.5 \\
\cline { 2 - 4 } & intermediate & 19.5 & 30.0 \\
\cline { 2 - 4 } & junior & 72.5 & 41.7 \\
\hline
\end{tabular}

(1) Government investment: A linear unconditional latent variable growth model of government health expenditure from 2011 to 2016 in 8 underdeveloped provinces (Guizhou, Yunnan, Sichuan, Shanxi, Gansu, Qinghai, Ningxia and Xinjiang) was established to examine whether the government health expenditure showed linear growth (Figure 3$)$. The fitting of the unconditional model was as follows: ${ }^{2}=$ $72.280 \rrbracket d f=16, p \otimes 0.001, C F I=0.797, \mathrm{RMSEA}=0.663, \mathrm{SRMR}=0.034)$. The statistical results of the model were shown in Table 2. The following results was uniformly retained for three decimal places due to the small statistic associated with the slope. Table 2 shows that the intercept of the model, that was, the initial level of government health expenditure, was 176.247, which was significantly greater than 0 ( $p<$ 0.001 ); The slope average value was $33.203, p<0.001$, indicating that the government health expenditure showed a linear growth trend in 2011 2016, that was, the average annual increase of government health expenditure was about three billion three hundred and twenty million three hundred thousand yuan. In addition, the variance of intercept was $11999.941, \mathrm{p}<0.05$, which indicated that there was a significant difference between provinces in the level of government health expenditure. Therefore, it is necessary to continue to observe which factor leads to individual differences in development level. And there was a significant correlation between intercept and slope $(t=17.606, p<0.001)$, indicating that the growth rate of government health expenditure was related to the initial level of government health expenditure.

\section{Figure 3 Model of linear unconditional latent variable growth of government health expenditure}

\section{Table 2 Results of parameter estimation of latent variable growth curve model}




\begin{tabular}{|c|c|c|c|c|c|}
\hline item & & $\beta$ & S.E & $\mathrm{t}$ & $\mathrm{P}$ \\
\hline \multirow[t]{2}{*}{ intercept } & mean & 176.247 & 38.563 & 4.570 & 0.000 \\
\hline & variance & 11999.941 & 5948.499 & 2.017 & 0.044 \\
\hline \multirow[t]{2}{*}{ slope } & mean & 33.203 & 6.622 & 5.014 & 0.000 \\
\hline & variance & 352.308 & 172.759 & 2.039 & 0.041 \\
\hline Intercept and slope & covariance & 0.937 & 0.053 & 17.606 & 0.000 \\
\hline
\end{tabular}

(2) In the equation of unconditional model, we add the conditional model of per capita disposable income in 2013 2016 to examine whether the per capita disposable income causes the provincial difference in the initial level of government health expenditure and the speed of change. The fitting index between the model and the data was as follows: $\left({ }^{2}=229.687\right.$ df $=17, p<0.001, \mathrm{CFI}=0.426, \mathrm{RMSEA}=1.251, \mathrm{SRMR}=$ 0.194). The statistical results of the model are shown in Table 3 . The results shows that, the average disposable income had no predictive effect on the government health expenditure in the same period $(p<$ 0.05).

\section{Table 3 The role of per capita disposable income in forecasting government health expenditure for the same period}

B S.E $\quad \mathrm{t} \quad \mathrm{P}$

Government health expenditure2013-per capita disposable

$$
\begin{array}{llll}
0.095 & 0.032 & 2.917 & 0.004
\end{array}
$$

income 2013

Government health expenditure2014-per capita disposable

$$
0.057 \quad 0.022
$$

2.569

0.010

income 2014

Government health expenditure2015-per capita disposable $\begin{array}{llll}0.048 & 0.018 & 2.664 & 0.008\end{array}$ income 2015

Government health expenditure2016-per capita disposable

0.018

0.023

0.791

0.429 income2016

4. Farmers' satisfaction with and willingness to participate in NRCMS

(1)Only $22.9 \%$ of the households thought it convenient, while $77.1 \%$ thought it too complicated or not worth it. 
(2) $50.92 \%$ think the compensation is very helpful, while $49.08 \%$ think it of little help or no help at all.

(3)Only $26.6 \%$ think that the financial burden of diseases is relieved, while $57.3 \%$ think that the relief is not obvious, and the remaining $16.1 \%$ said the system had no effect at all.

(4)Some farmers still have a wait-and-see attitude towards NRCMS: $44.1 \%$ of farmers are worried about reimbursement ratio of the new system is too low to solve the problem of excessive medical costs. Another $16.7 \%$ of farmers worry about doctors' bad attitudes, and $17.2 \%$ of farmers are unaware of the system.

\section{Discussion}

The NRCMS is a crucial step in narrowing the insurance gap and improving equity in access to healthcare for rural populations in China. Through years of development, the security level and coverage of the scheme have been greatly increased and enlarged[11]. However, according to the data, per capita disposable income in the western region remained the lowest of the four regions in China by 2015. The appearance of this phenomenon is not only related to the geography and traffic environment of the western region itself, but also closely related to the development strategy carried out by Chinese government[12]. In terms of geographical environment and traffic conditions, the western region is deeply inland, with terrain of mainly plateau, and mountain-based, and its water source is limited, meaning that it is not conducive to the needs of human survival, production and large-scale economic and industrial construction. At the same time, single railway and highway conditions make it difficult to form trade advantages to promote regional economic development [13]. In terms of national policies, after the 1980 s, the state implemented the strategy of speeding up the development of coastal areas, and the economic development of the eastern coastal areas accelerated. By the 1990s, the income of urban residents in the eastern part of the country had greatly increased, and the income of urban residents in the eastern region had greatly increased [14]. The income gap between the western region and eastern region has widened. Although since the reform and opening up to the outside world, the economic system was adjusted and the market economy system was established. However, because of its position, crossborder investment and overseas trade could not benefit the region, which further widened the economic level gap between the western region and the eastern region[15].

In addition, the study shows that the proportion of per capita medical expenditure in the western rural areas between 2000 and 2015 is also increasing year by year. As a result of the higher education level, quality training, medical facilities and services of the urban residents, compared with the rural areas, the structural differences between the urban and rural dualism are finally formed [16,17]. In addition, under the influence of many factors such as resource environment and historical culture, the further development of the western region has been restricted, resulting in a significant difference in the level of social security between rural and urban areas [18]. So, if there is a lack of financial input in rural areas' social security in the system, especially for the farmers who lack of public medical security, the increasing costs of diagnosis and treatment will lose touch with reality of the farmers' actual ability, and even makes 
them unable to pay alone. Therefore, developing countries should pay attention to improving the skills of rural residents in order to increase their productivity, income and profits. At the same time, the financing policies should be adjusted to narrow the gap between urban and rural residents.

This study shows that by the end of 2015 , the average common bed space in rural areas of eight provinces is lower than the national standard. From the macro level, this phenomenon is mainly due to the serious shortage of local financial input, resulting in a large amount of infrastructure debt [19]. In the medical institution system of the central and western backward areas, because of the weakening of the original rural collective economic base, the capital input is not guaranteed, the management system is loose, and the facilities of the village health rooms are changed from the public to the private individual medical treatment points [20]. Medical equipment, diagnosis and treatment procedures, and other hardware and software facilities can not meet the national standards is a long-standing reality. Therefore, various public health funds and business development funds should be included in the budget, and with the increase of fiscal revenue, the proportion of investment should be gradually increased [21]. Through the financial investment of the government, the township health centers can be provided with medical equipment suitable to the rural reality, and the treatment ability and the level of treatment can be continuously improved. In addition, we should pay attention to the management and management of the existing rural medical and health resources, and effectively providing low-cost, high-quality medical and health care services to the vast number of farmers [22].

The level of education and specialty of medical staff in poor rural areas is generally low. This may be due to the low level of rural economy, low potential for development, highly educated medical workers believe that these areas are not developed, and pay is not high. In addition, the current national treatment policy in these areas is not attractive to senior health technicians, which is one of the important reasons for the lack of medical resources in the western region [23]. There is no alternation between the old and the new, and the structure of the medical staff is aging [24]. At the same time, there is a lack of necessary followup continuing education and training to current personnel, which means health care personnel do not understand the new medical and health technologies, and new means. [25] In this regard, how to realize the primary purpose is to create a high-quality, skilled grass-roots physicians? First, the establishment of village doctors professional qualifications admission mechanism, rural doctors must have professional qualifications or professional (assistant) physician qualifications; The second is to strengthen the rural primary health care personnel training, establish a life-long education system[26]. We can make full use of the three-level medical service network, and the rural health technicians at the grass-roots level regularly rotate to urban medical institutions for free training and further education, and at the same time, urban health technicians take turns in stages. Batch to the designated township health centers for technical support and assistance, and then achieve talent interaction[27]. Finally, improve the technical service ability and level of rural health personnel, promote the rapid development of rural health.

According to the survey of eight provinces from the perspective of government health expenditure. The results of this study show that the annual government health expenditure increases linearly in 20112016, and the difference between provinces is obvious. Because this model shows that the level of 
government health expenditure is related to the initial health expenditure and growth rate, and the initial health expenditure is significantly correlated with the growth rate $(t=17.606, p<0.001)$, The difference of initial health expenditure is one of the reasons for the difference of government health expenditure among provinces. This is related to the financial pressure between different regions, where the level of fiscal revenue exists. Fundamentally, the difference is caused by the different levels of economic development in various regions, and is a manifestation of the irrational economic structure [28].The financing level of NRCMS is slightly different because of the difference of economic conditions among different regions. At first, the provinces with lower economic ability have lower investment in health resources, which also aggravates the pressure of residents in poor areas to get good social security. [29]. Therefore, the state should strengthen the adjustment of the balanced development of the regional economy, promote the balanced development of the regional economy, and solve all kinds of problems brought about by the unreasonable structure of the regional economy.

In addition, the study shows that per capita disposable income in 2013-2015 has a significant predictive effect on government health expenditure in the same period. This phenomenon may be due to the increase or decline in per capita disposable income, which determines whether residents have more capital to pay attention to medical conditions and the protection of their own health and. In turn, to propose the need for basic medical facilities and services, this requires the government to consciously adjust its investment in health care over the same period [30]. At the same time, the increase or decline of farmers' disposable income means whether the government also has the corresponding disposable funds and the ability to strengthen the construction of medical care during the same period. Long term, the administrative function of the government is too prominent, and the absence of the public service function leads to the weakening of the rural medical and health service system. Therefore, for the underdeveloped areas, from the management-oriented government to the service-oriented government, the promotion of public functions such as education, health care and other public functions is a large number of farmers in urgent need of public services [31]. Only in this way can the rural medical service and insurance system be improved for a long time. If we do not break the "bottleneck" of the system and mechanism, it will have a great impact on the reform of rural social medical security.

Farmers as the main object of the NRCMS, their satisfaction with this system is one of the important indicators of evaluation. In this study, farmers' overall satisfaction with the new rural cooperative medical care is not very high. In poor areas, due to the lack of public health services, the new system should have given greater benefit to the poor. Qi[32]suggests that the NRCMS decreased the poverty rate significantly and raised wealth for middle and low income families. Guo[33] found there existed inequality in reimbursement, saying that the reimbursement rate and ceiling benefited high income groups from getting more reimbursement. The technical level in rural hospitals is limited. For outpatients, usually the reimbursement rate is low. As for inpatients, they can only get the reimbursement certification from hospital after they discharge from hospital, especially for the long-stay patients. And many examinations and approvals are needed from every level of health care institutions. It may take at least one month to get compensation expenses after handing in the application. In addition, the technical level of rural hospitals is limited, and if participants need more medical services and move to higher-level hospitals, 
usually large hospitals in the city, the way to get compensation is too difficult. They can be compensated within a week or two after a designed hospital is treated. At the same time, in order to make full use of the limited funds, the amount of payment, the limit and the ratio of compensation are set when the hospital expenses are compensated[34]. In the case of high compensation rate and low upper limit, the compensation obtained by farmers is far from enough with structure. At present, government subsidies and complex reimbursement process are weakening the application and attractiveness of the system.

Various analyses have shown that the farmers' will of participation is influenced more by subjective factors. Due to the fail of traditional cooperative medical care, the farmers have different worries about the future sustain of NRCMS. Worried about the stability of the system, they thought the expected return was low so they waited and saw it uncooperatively. Mao's study showed that $67 \%$ of the non-participating farmers chose not to participate because they did not understand the new system [35]. When they find themselves enforced and unable to express their true opinions, they choose to participate passively. The emergence of this phenomenon, on the one hand, shows that advocacy is insufficient, on the other hand, the capacity of regulators appears to be weak, and there is a lack of effective financial restraint mechanisms and regulatory measures [36]. In order to increase participation, many local governments have chosen not to provide sufficient funding, compensation and other details, some even exaggerating the effect which masked the defects of the system, resulting in farmers lack of detailed information [37]. In addition, as an important beneficiary group, and lack of resilience to economic risks, farmers have a strong willingness to obtain financial protection. In the supervision mechanism established by the government, farmers' participation space is relatively small, which limits the scope of farmers' participation.

According to the game theory, each stakeholder will try to maximize its gain or to rationally receive a better future result in the process of regulation deciding. The stakeholders will interact with each other to a balance point and then new regulations will be formed. As a systematic project, the stakeholders in the NRCMS consists of the farmers, medical institutions, agencies and the government. Farmers are the foundation of the system, medical institutions are providers of medical services and medical insurance, and the government is the regulator. The success of the scheme depends on the coordination of the relationship among them. If the wealth not benefits the farmers but other members, properly the scheme isn't being used optimally. Therefore, medical institutions, insurance agencies, governments and farmers should not be opposed to each other. A balanced and coordinated mechanism of interest linkage should be formed.

\section{Conclusion}

Although modified NRCMS policies could reduce medical financial burden for rural residents to some extent, the protection effectiveness was still limited, and the result of NRCMS reimbursement aggravated health inequity. First of all, policymakers should pay attention to improving the skills and knowledge of rural residents in order to reduce the gap of the education level between urban and rural residents.

Secondly, it is an important way in improving medical service in poor areas to build a team of grass-roots 
doctors with high quality and excellent technology, and to solve the worries of rural doctors. In addition, the local government plays an irreplaceable role in regulating and controlling the implementation and perfection of the policy. While strengthening the publicity of the new policy, it is also necessary to strengthen the supervision of medical institutions and do a good job in the relevant investment and expenditure of funds, to ensure the maximization of the interests of the people. Therefore, medical institutions, insurance institutions, governments and farmers should not be opposed to each other, forming a kind of flat balanced and coordinated mechanism of interest linkage appears to be of vital importance.

\section{Abbreviations}

NRCMS $₫$ New Rural Cooperative Medical System

\section{Declarations}

\section{Acknowledgements}

The authors express thanks to the National Natural Science Foundation of China and the Shenyang Philosophy and Social Science Key Project for their financial help.

\section{Funding}

The authors received financial support of National Natural Science Foundation of China (71673299), and the Shenyang Philosophy and Social Science Key Project (18014).

\section{Availability of data and materials}

The database generated during and/or analyzed during the current study are available from the corresponding author on reasonable request.

\section{Authors' contributions}

PY and YW designed the whole process and did the pre-research. PY, YW and JOY were the main drafters of the manuscript. SS did some of the expeditionary research. SS contributed the coordination and manuscript editing. All participated in the analysis and discussion of the topic, under the leadership and instruction of SS. All authors read and approved the final manuscript.

\section{Ethics approval and consent to participate}


The study was supported by the Ethics Committee of the Ministry of Health of China区[2013] 062『 and they claimed that they approved this study. All procedures performed in studies involving human participants were in accordance with the ethical standards of the institutional and national research committee and with the 1964 Helsinki declaration and its later amendments or comparable ethical standards. All the participants agreed our investigation request and each participant signed on their consents which were recorded and kept properly by the Ethics Committee of the Ministry of Health of China.

\section{Consent for publication}

The manuscript is approved by all authors for publication. The manuscript was an original research that has not been published previously, nor under consideration for publication elsewhere, neither in whole or in part.

\section{Competing interests}

No conflict of interest exits in the submission of this manuscript, and manuscript is approved by all authors for publication.

\section{References}

1. CS Hendrix, S Haggard. March. Global food prices, regime type, and urban unrest in the developing world. Journal of Peace Research. 2015;52(2):143-157. doi: 10.1177/0022343314561599

2. World Bank. http: //data. 2018. worldbank.org/indicator/SP.RUR.TOTL. Accessed Mar 15, 2016.

3. World Bank. http://data. 2018. worldbank.org/indicator/SP.RUR.TOTL.ZS. Accessed Mar 15, 2016.

4. People's Daily. Decisions of the Central Committee of the Communist Party of China on further strengthening agricultural and rural work. [http://www.people.com.cn/GB/shizheng/252/5089/5105/5191/20010429/455924.html]

5. Ministry of Health, Ministry of Finance, Ministry of Agriculture. Notice on the Establishment of New Rural Cooperative Medical System. [http://www.chinaacc.com/new/63/74/2003/1/ad7387345011161130022538.html]

6. Bai CE, Wu BZ. Health insurance and consumption: evidence from China's new cooperative medical scheme. J Comp Econ. 2014;42(2):450-469. doi:10.1016/j.jce.2013.07.005

7. Shao Dexing. An study on supply model of the New Rural Cooperative Medical System. Beijing: Central Party School Press, Inc; 2007. pp. 240-245.

8. Babiarz KS, Miller G, Yi H, Zhang L, Rozelle S.New evidence on the impact of China's New Rural Cooperative Medical Scheme and its implications for rural primary healthcare: multivariate difference-in-difference analysis.BMJ.2010; 341: c5617. doi: 10.1136/bmj.c5617. 
9. Hou Z, Van de Poel, Van Doorslaer E, Yu B, Meng Q. Effects of NCMS on access to care and financial protection in China. Health Economics. 2014;23(8):917-934. doi: 10.1002/hec.2965

10. Cheung Diana, Padieu Ysaline. Heterogeneity of the Effects of Health Insurance on Household Savings: Evidence from Rural China. World Development. 2015;66:84-103. doi: 10.1016/j.worlddev.2014.08.004

11. Xiang Li, Hong Cai, Chaoyi Wang, Chuanhai Guo, Zhonghu He, Yang Ke. Economic burden of gastrointestinal cancer under the protection of the New Rural Cooperative Medical Scheme in a region of rural China with high incidence of oesophageal cancer: cross-sectional survey. Tropical Medicine International Health.2016;21(7):907-916. doi: 10.1111/tmi.12715

12. Zhou ZY. The Main Reasons for the Widening of the Economic Gap between the Middle, Eastern and Western Regions of China. China Venture Capital.2017;36:237. doi: 10.3969/j.issn.16735811.2017 .36 .207

13. Ma N, Xu YX. On the Differences in Spatial Structures of Regional Economy between the East and West of China and the Relevant Optimization Strategies. Journal of Baoji University of Arts and Science (Social Science Edition).2017;37(1):124-127. doi: 10.13467/j.cnki.jbuss.2017.01.025

14. Zhang Qinghua,Huang Zhijian,Guo Shufen. The difference of Regional Economic Development and Prediction of catch-up Model. Statistics and Decision.2017;(15):146-149. doi: 10.13546/j.cnki.tjyjc.2017.15.035

15. He Yanzi, Wang Huanfang, Liu Jiawen. An Empirical Analysis of Regional Economic Development Differentiation in Chinese Eastern, Middle and Western Regions. Journal of Nanchang Hangkong University (Social Science Edition). 2016;18(3):48-54,112. doi: 10.3969/j.issn.10091912.2016.03.008

16. Wang Y, Liu Y, Li Y, Li T. The spatio-temporal patterns of urban-rural development transformation in China since 1990. Habitat International. 2016;53(53):178-187

17. Ann T, Wu Y, Zheng B, Zhang X, Shen L. Identifying risk factors of urban-rural conflict in urbanization: a case of China. Habitat International. 2014;44:177-185.

18. Kun Zhu, Luying Zhang, Shasha Yuan,Xiaojuan Zhang, Zhiruo Zhang.Health financing and integration of urban and rural residents' basic medical insurance systems in China. Int J Equity Health. 2017; 16: 194.22. doi: 10.1186/s12939-017-0690-z.

19. Yu Jiali, Qian Zhiwang. Investment gap in health care industry and the temporal-spatial evolution of health service efficiency at provincial administrative institutions of China. Journal of Arid Land Resources and Environment. 2018; 32(8):59-66. doi: 10.13448/j.cnki.jalre.2018.236

20. Li Yingqin, Wang Qing. Study on Urban and Rural Medical and Health Resources Allocation Balance in China. Medicine and Society. 2016; 29(1):7-9. doi: 10.13723/j.yxysh.2016.01.003

21. Li Yang, Guo Feng, Zhao Yuxin. Analysis on Government Subsidies of Health Services on Western, Middle and Eastern Region of China in 2013. Health Economics Research. 2015;(4):9-12

22. Cai Yuanqing, Zhang Hongwen, Wang Wenjuan. The change and Optimization of Medical and Health Service Mode in China. Administration Reform. 2018;(12):100-107. 
23. Fang Huiying, Jiang Kexin, Li Peng.Thinking on Cultivation and Introduction of Health Human Resources in Poverty-Stricken Areas of Western China.Medicine and Society. 2018; 31(5):1-3. doi: 10.13723/j.yxysh.2018.05.001

24. Pan Lun, He Ping, Wu Jianhua, Deng Zhongquan, Gao Zhiping. Analysis and Countermeasure of Human Resources of Community Health Service Centers in the Small and Medium-sized Cities in Midwest China. Chinese General Practice. 2018; 21(32):3976-3981. doi: 10.12114/j.issn.10079572.2018.00.145

25. Teng Xiahong, Zhang Xinhua. Analysis of medical personnel allocation and medical doctor income in China.China Medical Herald. 2017;14(6):61-64.

26. Fu WQ, Liu GX, Wu QH, Hao M. Analysis on the Variation Trends of Medical Personnel Allocation in China Grass-root Medical Organizations under the Background of Medical Reform.Chinese Health Economics.2015;34(7):35-37. doi: 10.7664/CHE20150916

27. Zhang Yunfeng, Wang Yong. A Survey Research on the Primary Health Service Network in Less Developed Rural Areas. Journal of Chongqing University (Social Science Edition). 2014; 20(6):11-17. doi: $10.11835 /$ j.issn.1008-5831.2014.06.002

28. Song Guangjun. Measurement and Analysis of the Regional Financial Pressure of the New Rural Cooperative Medical System-A Case Study of the Midwest Region. Journal of Suzhou University. 2016;31(1):16-20.

29. Lu Jianlong, Qi Fangjia, Feng Sha, Wu Weidong, Dou Guanshen, Ying Xiaohua. Research on Equity of Health Financing in Rural Areas of China after the Implementation of New Rural Cooperative Medical System. Chinese Health Economics. 2014; 33(11):29-30. doi: 10.7664/CHE20141108

30. Hamamoto Song, He Gang, Fan Yancun. An Empirical Study on the Operating Efficiency of Medical Institutions in Western China under the Background of "New Medical Reform". Chinese Journal of Health Statistics.2017;34(6):912-914.

31. Li YingYing. On the Development of the New Agriculture in the View of the Participation of the Subject. Contemporary Rural Finance and Eeonomics.TU7 G40,15-17.

32. Liu X, Tang S, Yu B, Phuong NK, Yan F, Thien DD, et al. Can rural health insurance improve equity in health care utilization? A comparison between China and Vietnam. Int J Equity Health. 2012;14(1):10. doi: 10.1186/1475-9276-11-10.

33. Li Y, Wu Q, Liu C, et al. Catastrophic Health Expenditure and Rural Household Impoverishment in China: What Role Does the New Cooperative Health Insurance Scheme Play? PLOS ONE. 2014;9(4): e93253. doi: 10.1371/journal.pone.0093253.

34. Pan Li. The Actual Situation and Strategy Analysis of the New Rural Cooperative Payment Reform. Economig Rfsearch Cuide.2017;(17):F24 153-154.

35. Liang X, Guo H, Jin C, Peng X, Zhang X. The Effect of New Cooperative Medical Scheme on Health Outcomes and Alleviating Catastrophic Health Expenditure in China: A Systematic Review. PLOS ONE. 2012;7(8):e40850. doi: 10.1371/journal.pone.0040850. 
36. Chen Wenqin, Zhang Meng, Zhong Xingguang, Wang Xiaohe, Ji Hongyan, Du Li Qiang, Fan Libin.

Study on the Medical Service Providers'Interest Demands of the Payment System Reform in China's New Rural Cooperative Medical Care Scheme. Chinese Journal of Social Medicine. 2018;35(6):622625. doi: 10.3969/j.issn.1673-5625.2018.06.021

37. Deng Lin. On the Sustainable Development of the New Rural Cooperative Medical system in Western China-A case study of Shaanxi Province. 34.ZHISHI JINGJI.R19 TG5,52-52.

\section{Figures}

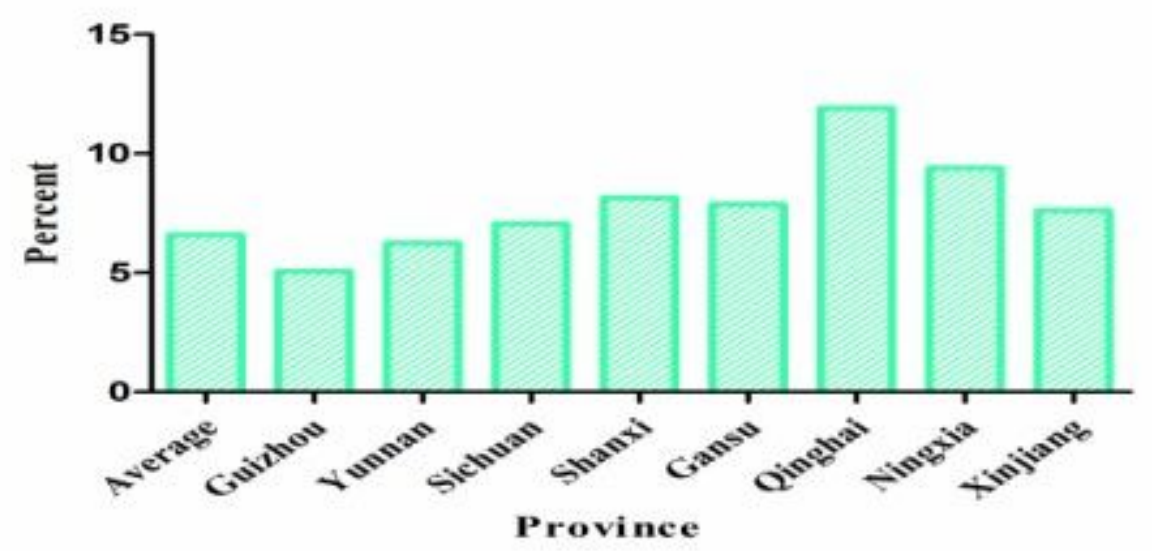

Figure 1 Per capita medical care expenditure as share of living expenditure of rural residents

\section{Figure 1}

Per capita medical care expenditure as share of living expenditure of rural residents

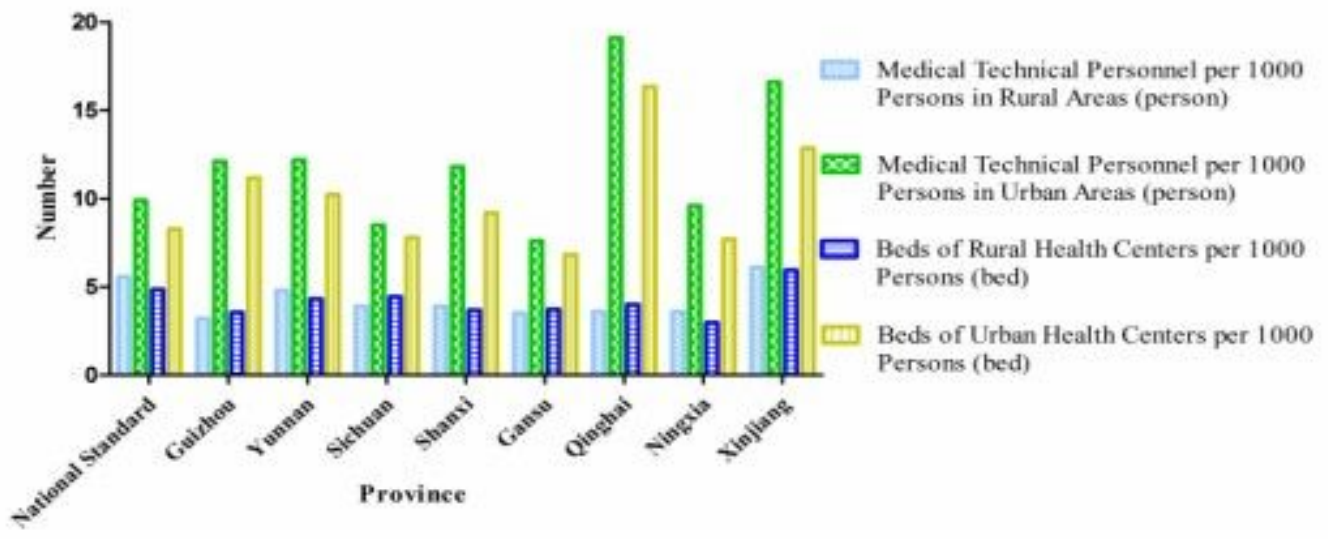

Figure 2 Number of medical devices and beds per 1,000 persons in urban and rural areas of eight provinces 


\section{Figure 2}

Number of medical devices and beds per 1,000 persons in urban and rural areas of eight provinces

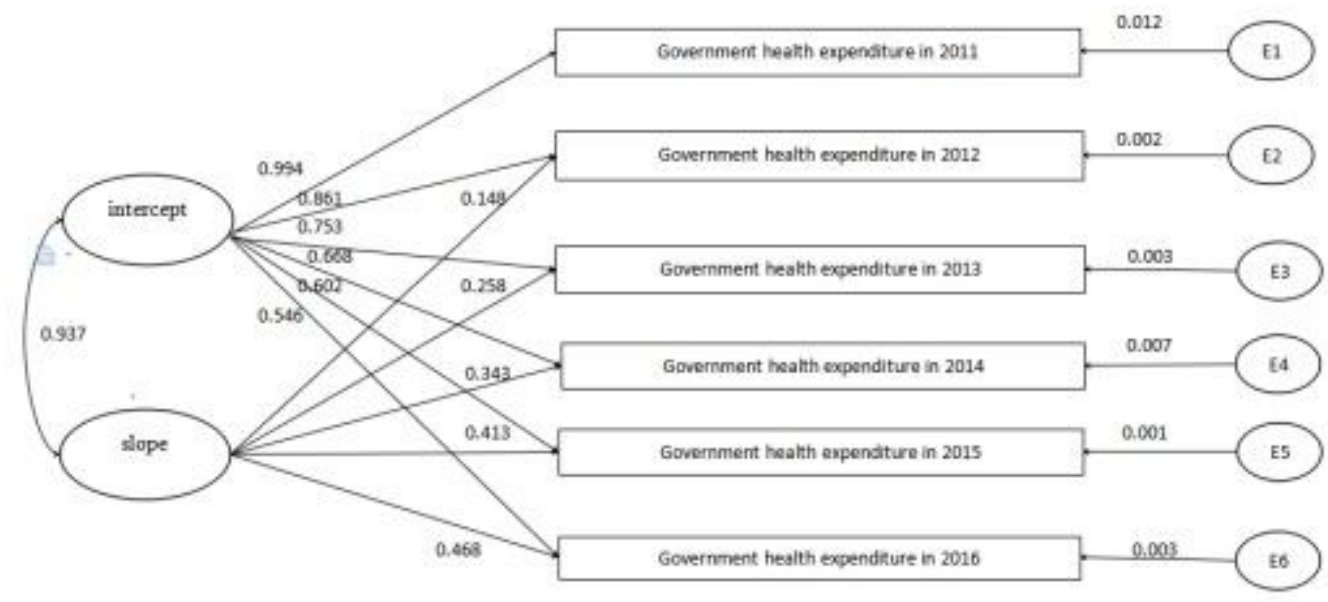

Figure 3 Model of linear unconditional latent variable growth of government health expenditure

\section{Figure 3}

Model of linear unconditional latent variable growth of government health expenditure 